\title{
Analisa Unjuk Kerja Generator Sinkron Tiga Fasa dengan Penggerak Turbin Angin
}

\author{
Rifdian I.S $\mathbf{1}$, Hartono ${ }^{2}$ \\ 1,2)Politeknik Penerbangan Surabaya \\ J1. Jemur Andayani I, No. 73 Surabaya 60236 \\ Email : rifdian.anto@gmail.com
}

\begin{abstract}
ABSTRAK
Energi angin merupakan salah satu sumber energi terbarukan yang ketersediaannya melimpah dan dapat menggantikan sumber energi fosil. Pertumbuhan permintaan energi angin mendorong untuk menghasilkan daya output berkualitas untuk mensuplai beban. Pemilihan turbin angin dan generator yang tepat diperlukan untuk memaksimalkan penangkapan energi angin. Generator sinkron tiga fasa merupakan salah satu tipe generator yang digunakan dalam sistem konversi energi angin. Pengaturan tegangan output generator sinkron tiga fasa diperlukan karena variasi naik turunnya tegangan dan frekuensi output generator akibat perubahan kecepatan putar generator dan perubahan pembebanan. Penelitian ini bertujuan untuk merancang disain rangkaian kontrol yang tepat pada generator sinkron tiga fasa dengan penggerak turbin angin dan melakukan analisa unjuk kerja pada rangkaian kontrol tersebut. Disain rangkaian kontrol tersebut terdiri dari tiga komponen utama yaitu rangkaian buck converter untuk eksitasi generator, rangkaian regulator tegangan untuk output generator dan kontroler logika fuzzy untuk eksitasi generator. Berdasarkan hasil pengujian yang telah dilaksanakan, generator menghasilkan tegangan dan frekuensi output yang stabil untuk berbagai variasi beban resistif yang diberikan. Hasil kinerja respon dari rangkaian kontrol logika fuzzy adalah 1,02 ms untuk delay time, 1,85 ms untuk rise time, 2,18 ms untuk peak time, 165,5 ms untuk settling time dan dengan maximum overshoot sebesar $5 \%$. Kinerja ini cukup baik untuk pengontrolan eksitasitasi generator dengan rangkaian buck converter.
\end{abstract}

Kata Kunci : Motor generator, generator sinkron tiga fasa, buck converter, regulator tegangan, kontrol logika fuzzy.

PENDAHULUAN

Energi angin menjadi salah satu sumber energi terbarukan yang terpenting karena bebas dari pencemaran lingkungan. Energi listrik yang dihasilkan oleh turbin angin memerlukan sebuah sistem konversi agar dapat dimanfaatkan pada berbagai aplikasi Salah satu teknologi yang digunakan yaitu sistem konversi energi angin (wind energy conversion system/WECS).

Penggunaan sistem WECS memiliki keuntungan yaitu peningkatan pembangkitan energi dan kualitas daya yang lebih baik.[1]. Sistem WECS menggunakan beberapa tipe generator listrik, yaitu Squirrel Cage Induction Generator (SCIG), Wound Rotor Induction Generator (WRIG), Double Fed Induction Generator (DFIG), Wound Rotor Synchronous Generator (WRSG), dan Permanent Magnet Synchronous Generator (PMSG). WRSG umumnya digunakan untuk aplikasi kecepatan angin variabel dan untuk mencakup variasi kecepatan angin yang lebar dengan menggunakan kontrol elektronika daya.[2] Ada dua tipe orientasi turbin yang digunakan untuk mengkonversi energi angin, yaitu horizontal axis wind turbine (HAWT) dan vertical axis wind turbine (VAWT). Hampir semua turbin angin modern menggunakan konfigurasi HAWT dengan jumlah blade tiga atau lebih. Turbin dengan 3 blade lebih umum digunakan karena kestabilan yang baik untuk beban simetris [3]. Elekronika daya / power electronics merupakan teknologi yang efisien untuk mengkonversi daya listrik, dan melaksanakan peran yang penting dalam sistem konversi energi angin. Komponen elektronika daya merupakan bagian terpenting 
dari pembangkitan energi angin dengan kecepatan variabel untuk mendapatkan efisiensi dan kinerja yang tinggi dalam sistem tenaga listrik.[4].

Pada penelitian ini, sistem motor dan generator digunakan untuk merepresentasikan turbin angin dan generator pada sistem konversi energi angin. Motor induksi sebagai representasi turbin angin akan diputar pada kecepatan putar (rpm) sesuai dengan turbin angin acuan.[5].

Tujuan penelitian ini adalah untuk merancang disain rangkaian kontrol generator sinkron tiga fasa dengan penggerak turbin angin dan melakukan analisa unjuk kerja rangkaian kontrol tersebut. Sistem generator sinkron tiga fasa dengan penggerak turbin angin pada penelitian ini terdiri dari tiga komponen utama yaitu rangkaian buck converter untuk eksitasi generator, rangkaian regulator tegangan untuk output generator dan rangkaian kontroler logika fuzzy untuk pengaturan buck converter. Sistem eksitasi generator dengan rangkaian buck converter memberi kemudahan dalam memberikan penguatan pada kumparan medan generator. Penggunaan buck converter ini berfungsi untuk pengatur tegangan eksitasi generator secara otomatis dengan mikrokontroler sebagai pengontrolnya. Pengaturan eksitasi ini dilakukan dengan mengendalikan nilai duty cycle pada pada buck converter sehingga tegangan output buck converter dapat diatur sesuai dengan tegangan eksitasi yang dibutuhkan. Sistem pengontrolan buck converter oleh mikrokontroler berbasis pada kontrol logika fuzzy dengan mikrokontroler Arduino Mega 2560 sebagai kontrolernya. Penggunaan kontrol logika fuzzy pada sistem ini memberikan beberapa keuntungan dan keunggulan dalam sistem pengendaliannya. Keuntungan tersebut adalah tidak diperlukannya model matematika yang rumit dari sistem, karena kendali logika fuzzy bekerja berdasarkan rule yang diekstrak sesuai dengan pemikiran dan pengetahuan manusia. Selain itu, kontrol logika fuzzy ini memberikan keunggulan antara lain memiliki adaptasi yang cepat terhadap perubahan parameter input, sistem operasi yang halus, serta kemampuan pendekatan yang baik terhadap nilai tegangan eksitasi yang dibutuhkan.

Selain didukung oleh pengontrolan eksitasi generator, pengaturan tegangan output generator sinkron tiga fasa juga diatur melalui regulator tegangan. Regulator tegangan ini berfungsi untuk menjaga tegangan output sistem menjadi lebih stabil dalam hal tegangan maupun frkuensinya sehingga tidak merusak beban AC yang terhubung ke rangkaian.

\section{SISTEM KONVERSI ENERGI ANGIN}

Sistem Konversi Energi Angin (SKEA) atau Wind Energy Conversion System (WECS) secara umum terdiri dari komponen pisau / blade, generator listrik, konverter elektronika daya, dan sistem kontrol. Hal ini ditunjukkan seperti gambar 1.

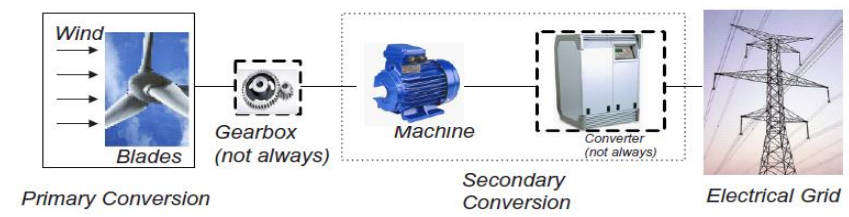

Gambar 1. Blok diagram SKEA/WECS[6]

Sesuai dengan gambar 1, generator listrik pada turbin angin berfungsi untuk mengubah energi mekanik dari rotor turbin menjadi energi listrik yang akan di suplai ke beban atau pun ke jaringan listrik yang lain. Beberapa macam generator telah digunakan bersama dengan turbin angin. Turbin angin kecil biasanya dilengkapi dengan generator arus searah (DC) dengan kapasitas sampai dengan beberapa kilowatt. Turbin angin modern telah menggunakan sistem tiga fasa dengan generator arus bolak-balik (AC).[6] 


\section{Generator turbin angin}

Secara umum, generator turbin angin dapat dibagi menjadi 2 kategori yaitu generator induksi dan generator sinkron. Keuntungan dari generator sinkron dibandingkan dengan generator induksi adalah dapat diaplikasikan untuk kapasitas daya yang besar, pengaturan tegangan generator yang lebih mudah dengan mengatur tegangan eksitasi, dan tidak deperlukannya kompensasi daya reaktif. Penggunaan generator sinkron tiga fasa lebih umum digunakan untuk menghasilkan kapasitas daya yang kebih besar dibandingakan dengan generator sinkron satu fasa. [2]

\section{Konverter elektronika daya}

Konverter elektronika daya digunakan untuk mengkonversi daya listrik pada turbin angin kapasitas kecil sampai besar. Konverter ini digunakan untuk mengontrol sudut fasa, amplitudo tegangan, frekuensi dan beberapa parameter lain pada generator trubin angin. Ada berbagai topologi konverter yang digunakan sesuai dengan karakteristik dari generator turbin angin, salah satu topologi konverter adalah sesuai gambar 2 yang digunakan pada tipe generator sinkron tiga fasa.[2]

Berdasarkan gambar 2, kumparan rotor pada generator sinkron tersusun dari rotor dengan kumparan terpisah untuk penguatan medan dan mendapatkan eksitasi dari sumber DC. Sistem ini sangat sesuai dengan pengontrolan daya dengan menggunakan konverter elektronika daya/power electronics. Karakteristik beban dan faktor daya dapat dikontrol dengan arus magnetisasi yang diperoleh dari eksitasi DC pada kumparan rotor.[2]

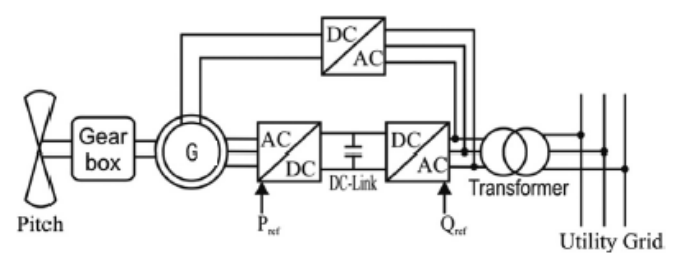

Gambar 2. Topologi konverter pada generator sinkron [2]

\section{Buck converter}

Dalam sistem turbin angin, buck converter digunakan untuk pengontrolan eksitasi DC pada generator. Hubungan tegangan input dan output pada buck converter dapat dinyatakan dengan duty cycle (D) yang dapat dirumuskan sebagai: $D=\frac{V_{o}}{V_{i}}$

Suply DC merupakan inputan dari buck converter dan tegangan kontrol eksitasi medan adalah merupakan output dari buck converter. Tegangan kontrol eksitasi ini akan mengatur tegangan output dari generator. [7]

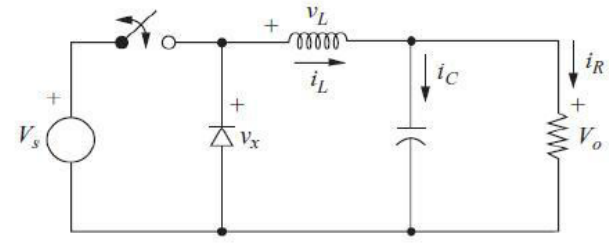

Gambar 3. Rangkaian buck converter [7] 


\section{METODOLOGI PENELITIAN}

\section{Sistem Motor Generator}

Sistem motor generator yang digunakan pada penelitian ini dapat ditunjukkan pada Gambar 4.

Sesuai dengan gambar 4, pada penelitian ini turbin angin digantikan dengan menggunakan motor induksi 3 fasa yang dapat diatur kecepatannya dengan menggunakan inverter. Variasi kecepatan putar ini disesuaikan dengan kecepatan putar (rpm) turbin angin acuan. Motor induksi tersebut dikopel dengan generator sinkron tiga fasa yang merepresentasikan generator pada sistem turbin angin. Tegangan output generator dikontrol dengan mengatur eksitasi DC pada kumparan rotor. Eksitasi DC pada kumparan rotor dikontrol dengan buck converter yang tegangan outputnya diatur dengan mengubah duty cycle. Pengontrolan buck converter menggunakan logika fuzzy. Output generator akan terhubung ke regulator tegangan sebelum mensuplai beban agar tegangan dan frekuensinya lebih stabil.

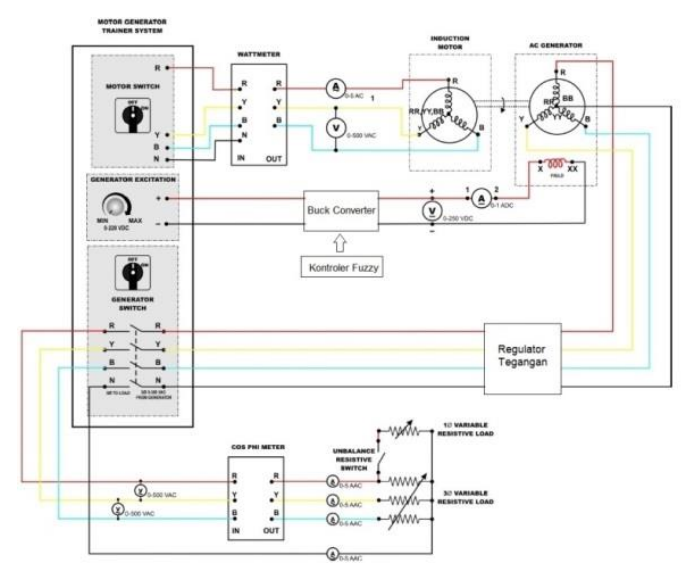

Gambar 4. Sistem motor generator [8]

Spesifikasi generator yang digunakan dalam penelitian ini adalah seperti pada tabel 1 .

Tabel 1..Spesifikasi generator yang digunakan[8]

\begin{tabular}{|l|l|l|}
\hline No & Spesifikasi & $\begin{array}{l}\text { Generator } \\
\text { AC }\end{array}$ \\
\hline 1 & Tipe & $\begin{array}{l}\text { Generator } \\
\text { Sinkron }\end{array}$ \\
\hline 2 & Frequency & $50 \mathrm{~Hz}$ \\
\hline 3 & RPM & $1500 \mathrm{rpm}$ \\
\hline 4 & VA/HP & $\begin{array}{l}746 \mathrm{VA} / 1 \\
\text { HP }\end{array}$ \\
\hline 5 & Ampere & $\begin{array}{l}1 / 1.7 \\
\text { Ampere }\end{array}$ \\
\hline 6 & Voltage & $\begin{array}{l}415 / 220 \\
\text { Volt }\end{array}$ \\
\hline 7 & Excitation & $\begin{array}{l}0-220 \\
\text { Vdc }\end{array}$ \\
\hline 8 & Phase & 3 \\
\hline 9 & Winding & Star/Delta \\
\hline
\end{tabular}


Spesifikasi motor yang digunakan dalam penelitian ini adalah seperti pada tabel 2.

Tabel 2. Spesifikasi motor yang digunakan[8]

\begin{tabular}{|l|l|l|}
\hline No & Spesifikasi & $\begin{array}{l}\text { Motor } \\
\text { Induksi }\end{array}$ \\
\hline 1 & Tipe & $\begin{array}{l}\text { Squirrel } \\
\text { Cage }\end{array}$ \\
\hline 2 & Frequency & $50 \mathrm{~Hz}$ \\
\hline 3 & RPM & $1420 \mathrm{rpm}$ \\
\hline 4 & VA/HP & $\begin{array}{l}746 \mathrm{VA} / 1 \\
\text { HP }\end{array}$ \\
\hline 5 & Ampere & $\begin{array}{l}2 / 3.4 \\
\text { Ampere }\end{array}$ \\
\hline 6 & Voltage & $\begin{array}{l}415 / 220 \\
\text { Volt }\end{array}$ \\
\hline 7 & Excitation & $\begin{array}{l}0-220 \\
\text { Vdc }\end{array}$ \\
\hline 8 & Phase & 3 \\
\hline 9 & Winding & Star/Delta \\
\hline
\end{tabular}

\section{Kecepatan putar generator turbin angin acuan}

Penelitian ini diawali dengan penentuan kecepatan putar generator turbin angin sesuai data yang diperoleh dari penelitian sebelumya. Generator ini diputar oleh turbin angin dengan spesifikasi sebagai berikut :

1. Baling-baling (blade) dengan panjang $70 \mathrm{~cm}$ dan lebar $20 \mathrm{~cm}$ dari bahan fiberglass berjumlah 4 dan 3 buah sebagai penggerak.

2. Roda gigi (gearbox) dengan perbandingan jari-jari 1:2

3. Tiang penyangga dengan tinggi $3 \mathrm{~m}$.

4. Generator magnet permanen sebagai pembangkit listrik saat pengujian.

Berdasarkan hasil pengujian turbin axial 3 bilah dan 4 bilah diperoleh data bahwa kecepatan angin adalah antara $3 \mathrm{~m} / \mathrm{s} \mathrm{s} / \mathrm{d} 6 \mathrm{~m} / \mathrm{s}$ dan kecepatan putar generator pada kecepatan angin tersebut adalah antara $432 \mathrm{rpm} \mathrm{s} / \mathrm{d} 807 \mathrm{rpm}$. Data pengujian pada turbin angin axial 3 bilah dapat dilihat pada gambar 5. Pengujian tersebut dilakukan pada tanggal 19 April 2012 di kota Surakarta.

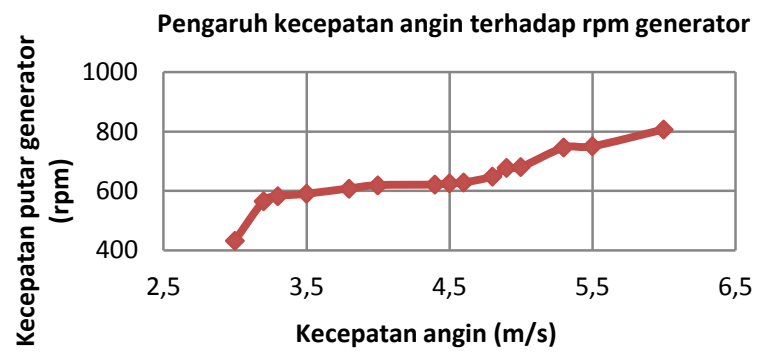

Gambar 5. Hasil pegukuran turbin angin axial 3 bilah [9] 
Data kecepatan putar generator pada turbin axial 3 bilah dipilih karena memiliki data yang lebih bervariasi untuk kecepatan angin dari $3 \mathrm{~m} / \mathrm{s}$ s/d 6 m/s.[9]

\section{Perancangan buck converter untuk eksitasi generator}

Tegangan eksitasi generator diatur dan dikontrol menggunakan buck converter. Output dari buck converter ini terhubung ke kumparan medan dari generator. Tegangan output dari generator dapat diatur dengan menurunkan atau menaikkan tegangan ouput dari buck converter. Sistem ini secara umum dapat digambarkan pada gambar berikut :

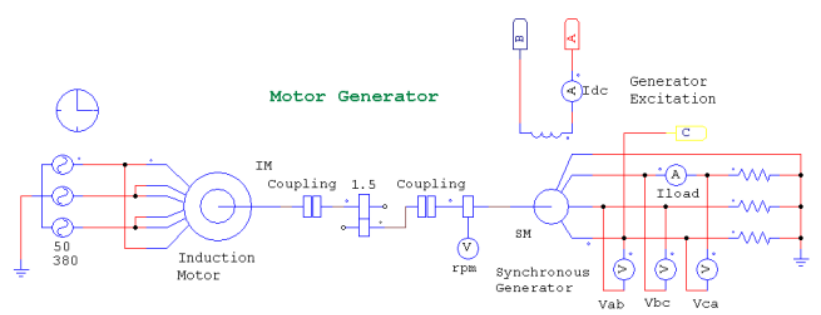

Gambar 6. Rangkaian motor generator [10]

Rangkaian buck converter dapat diimplementasikan sesuai gambar 7.

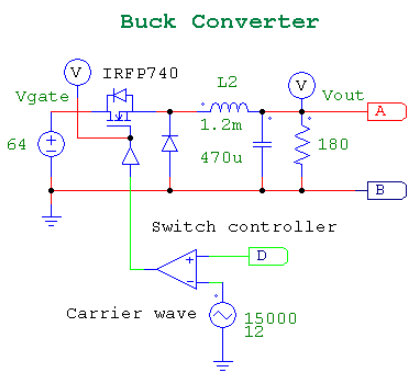

Gambar 7. Rangkaian buck converter [10]

Sesuai gambar 6, rangkaian dc-dc buck converter terdiri dari sebuah dioda, sebuah MOSFET IRF740, sebuah induktor $L$, sebuah kapasitor $C$, dan sebuah resistor $R$. Nilai induktansi pada induktor dihitung melalui persamaan 2, nilai kapasitansi pada kapasitor dihitung melalui persamaan 3, dan nilai resistansi pada resistor dihitung melalui persamaan 4. $f s$ merupakan frekuensi switching sebesar $15 \mathrm{kHz}$ dan $\Delta V$ adalah riak tegangan yang diinginkan [10]

$L=\frac{(1-D) \times V_{0}}{2 \times f_{S} \times I_{0}}$

$C=\frac{V_{o}(1-D)}{8 \times L \times f_{S}^{2} \times \Delta V_{0}}$

$R=\frac{V_{O}}{I}$

\section{Pengontrolan buck converter untuk eksitasi generator dengan logika fuzzy}

Besar kecilnya eksitasi generator/output buck converter ditentukan oleh nilai rpm generator dan nilai tegangan output generator. Perencanaan kontroler fuzzy menggunakan tiga buah parameter yaitu rpm generator, tegangan output generator dan tegangan eksitasi. Parameter input yaitu rpm generator dan tegangan output generator. Parameter outputnya yaitu tegangan eksitasi generator. 
Membership function untuk rpm generator terbagi menjadi 3 yaitu LR (Low Rpm), MR (Medium Rpm), dan HR (High Rpm) sesuai gambar 8.

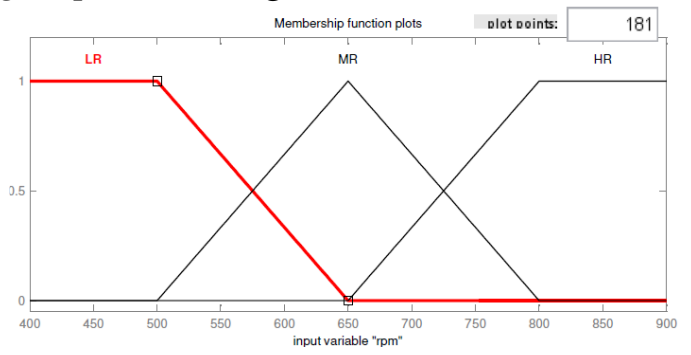

Gambar 8. Membership function rpm generator

Membership function untuk tegangan ouput generator terdiri dari 3 keanggotaan yaitu LV (Low Voltage), MV (Medium Voltage) dan HV (High Voltage) sesuai gambar 8.

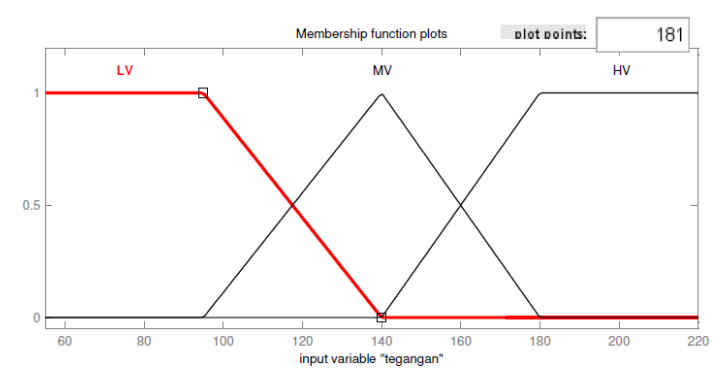

Gambar 9. Membership function rpm generator

Eksitasi generator merupakan output dari logika fuzzy. Eksitasi ini terdiri dari 3 kondisi yaitu LE (Low Excitation ), ME (Medium Excitation) dan HE (High Excitation) sesuai dengan rule base pada tabel 4.

Tabel 4. Rule based eksitasi

\begin{tabular}{|c|c|c|c|}
\hline $\begin{array}{c}\text { Rpm } \\
\text { Tegangan }\end{array}$ & LR & MR & HR \\
\hline LV & HE & HE & HE \\
\hline MV & ME & ME & ME \\
\hline HV & LE & LE & LE \\
\hline
\end{tabular}

Rangkaian kontrol fuzzy ini dapat digambarkan dan diaplikasikan pada gambar 9 dengan menggunakan mikrokontroler Arduino Mega 2560.

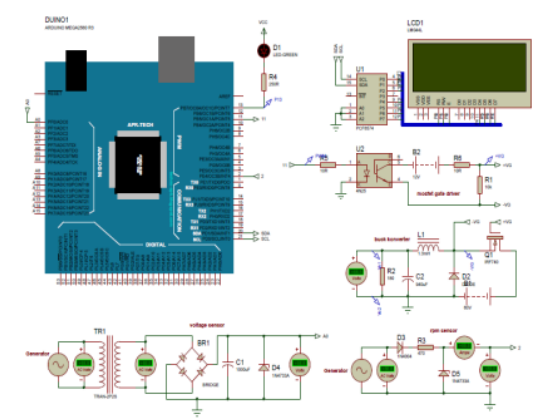

Gambar 10. Rangkaian kontrol fuzzy dengan Arduino Mega 2560 
Sesuai dengan gambar 9, rangkaian kontrol logika fuzzy ini terdiri dari mikrokontroler Arduino Mega sebagai kontroler, rangkaian buck converter yang dikontrol tegangan outputnya untuk eksitasi generator, rangkaian sensor tegangan dan rangkaian sensor rpm generator.

Mikrokontroler mendapatkan inputan tegangan dari sensor tegangan yang masuk melalui pin A0 (analog input). Inputan rpm dari sensor rpm masuk ke mikrokontroler melalui pin 2. Pemrograman fuzzy diupload ke mikrokontroler menggunakan software Arduino IDE. Output dari pemrograman fuzzy tersebut berupa nilai PWM pada pin 11 yang digunakan untuk menjalankan buck konverter sesuai dengan tegangan eksitasi yang dibutuhkan.

\section{HASIL DAN PEMBAHASAN}

Diagram rangkaian pengujian dari penelitian ini dapat ditunjukkan pada diagram rangkaian pada gambar 10. Komponen penting pada penelitian ini adalah rangkaian motor generator, rangkaian buck converter, rangkaian regulator tegangan dan kontroler logika fuzzy.

Sesuai gambar 10, eksitasi dari generator pada rangkaian motor generator akan dikontrol dengan buck converter. Tegangan output generator akan disensor dan diumpan balikkan untuk mendapatkan tegangan output sebesar $100 \mathrm{~V}$ melalui peningkatan eksitasi generator.

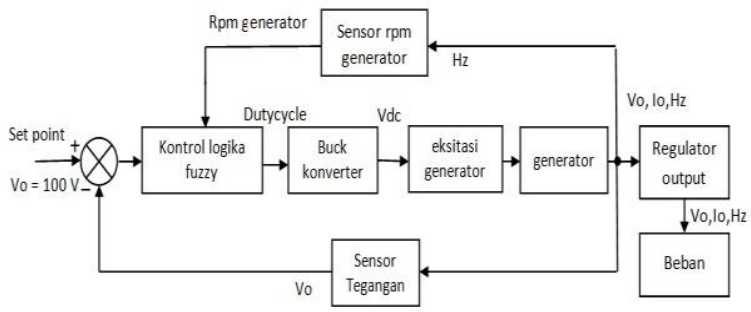

Gambar 11. Peralatan yang diuji dalam penelitian

\section{Pengujian buck converter}

Rangkaian buck converter menhasilkan tegangan output dc terkontrol sesuai dengan duty cycle yang diberikan. Tegangan output buck konverter ini digunakan untuk mengatur tegangan output generator melalui pengaturan tegangan esksitasi yang dimasukkan ke rotor.

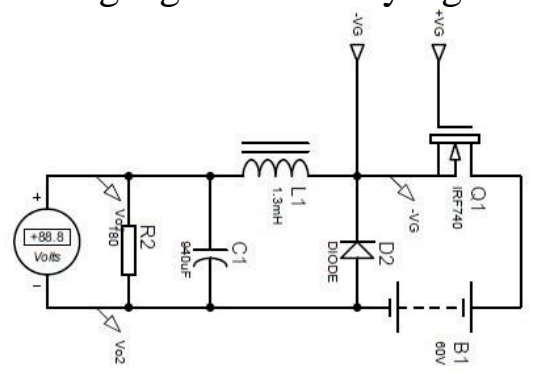

Gambar 12. Rangkaian buck converter

Tegangan output buck converter diatur oleh duty cycle yang dikontrol oleh mikrokontroler. Hasil pengujian ini dapat dilihat pada grafik gambr 13. 


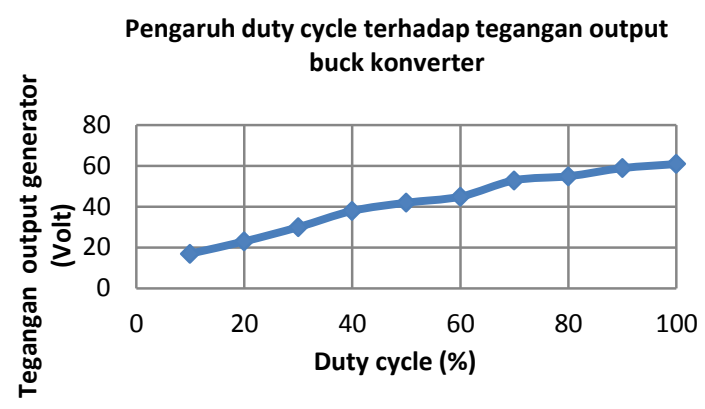

Gambar 13. Rangkaian buck converter

Berdasarkan gambar 12, input dari buck konverter berasal dari power suplai simetris dengan output maksimal $64 \mathrm{~V}$ dengan arus maksimal $7 \mathrm{~A}$. Output maksimal dari buck konverter adalah $60 \mathrm{~V}$ dengan arus maksimal $3 \mathrm{~A}$. Induktor yang digunakan memiliki rating $3 \mathrm{~A} 50 \mathrm{kHz}$. Rating dari induktor ini mencukupi untuk switching buck konverter dengan frekuensi switching $15 \mathrm{kHz}$.

\section{Pengujian sensor tegangan dan sensor rpm}

Pengontrolan tegangan eksitasi generator sangat ditentukan oleh output dari sensor tegangan dan sensor rpm.

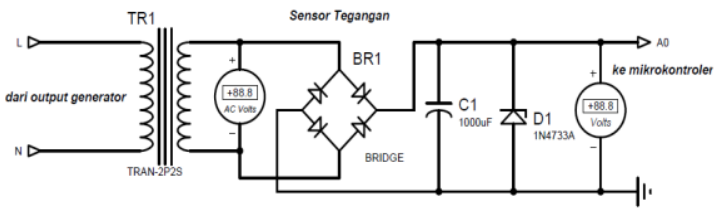

Gambar 14. Rangkaian sensor tegangan

Tegangan ouput generator bernilai antara 0-220 V diturunkan menggunakan transformator menjadi $0-5 \mathrm{~V}$. Tegangan tersebut kemudian disearahkan untuk dihubungkan ke analog input mikrontroler pada pin A0.

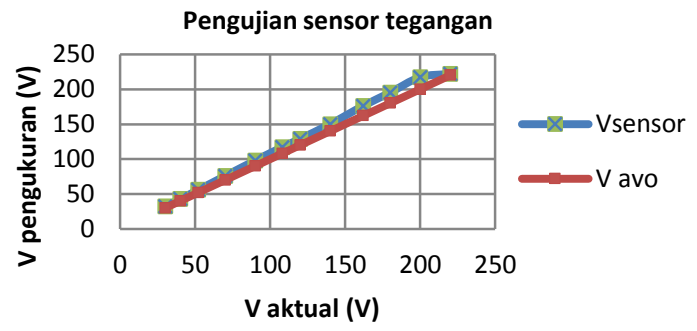

Gambar 15. Pengujian sensor tegangan

Berdasarkan gambar 14, nilai error pengukuran oleh mikrokontroler (Vsensor) dibandingkan dengan nilai tegangan sebenarnya (Vavo) masih akurat karena nilai error masih dibawah $10 \%$.

Sensor rpm komponen dasarnya adalah sebuah sensor frekuensi yang pada prinsipnya mendeteksi gelombang output tegangan AC ketika melewati titik nol dan titik maksimumnya. Berdasarkan durasi ketika melewati titik ini dapat diperoleh frekuensi tegangan AC tersebut. 


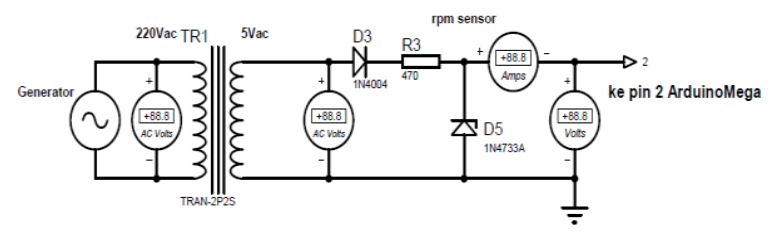

Gambar 16. Sensor rpm generator

Penentuan kecepatan generator diperoleh berdasarkan kecepatan putar pada mesin sinkron yang dirumuskan sebagai

$$
n=\frac{120 \times f}{p}
$$

Dimana $\mathrm{n}=$ kecepatan putar $(\mathrm{rpm}), \mathrm{f}=$ frekuensi tegangan, dan $\mathrm{p}=$ jumlah kutub/pole

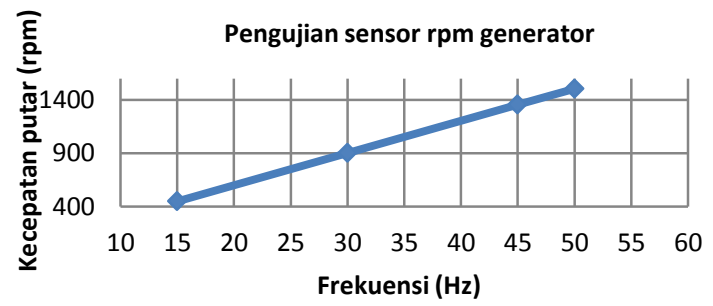

Gambar 17. Hasil pengujian sensor rpm

Berdasakan hasil pengujian sensor rpm, nilai frekuensi tegangan output generator memepengaruhi hasi pengeukuran rpm.

Generator sinkron yang digunakan memiliki 4 pole, frekuensi tegangan output yang diinginkan adalah $50 \mathrm{~Hz}$, sehingga dengan perhitungan kecepatan putar maksimum sesuai dengan persamaan (5) adalah :

\section{Pengujian regulator tegangan}

$$
n=\frac{120 \times 50}{4}=1500 \mathrm{rpm}
$$

Generator akan bekerja pada rpm yang berubah-ubah sehingga menghasilkan tegangan output yang juga berubah-ubah. Perubahan kecepatan putar generator akan berpengaruh pada frekuensi output generator. Frekuensi ini harus dijaga konstan agar tidak mengganggu beban. Untuk mengatasi frekuensi output yang berubah-ubah, digunakan kombinasi rectifier dan inverter yang dipasang sebelum beban. Kombinasi ini sering disebut dengan rangkaian back to back converter.

Nilai tegangan output generator yang berubah-ubah juga dapat mengganggu beban apabila terhubung secara langsung. Untuk mengatasi hal tersebut nilai tegangan generator harus dibuat konstan untuk kecepatan generator yang berubah-ubah. Pada rangkaian regulator tegangan ini digunakan transformator multi input dengan range tegangan mulai $55 \mathrm{~V}, 110 \mathrm{~V}, 165 \mathrm{~V}$, dan 220 V. Output dari transformator adalah konstan sebesar $0-24 \mathrm{~V}$. Secara umum rangkaian regulator tegangan output generator ini dapat dilihat pada gambar 17. 


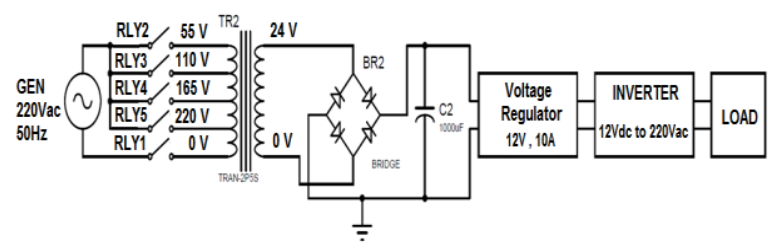

Gambar 18. Regulator tegangan output generator

Hasil pengujian rectifier dan voltage regulator dapat ditunjukkan pada gambar 18. Sesuai dengan gambar 18, output regulator terjaga konstan sebesar $14,5 \mathrm{~V}$ untuk berbagai variasi tegangan output generator (dalam hal ini adalah tegangan input trafo).

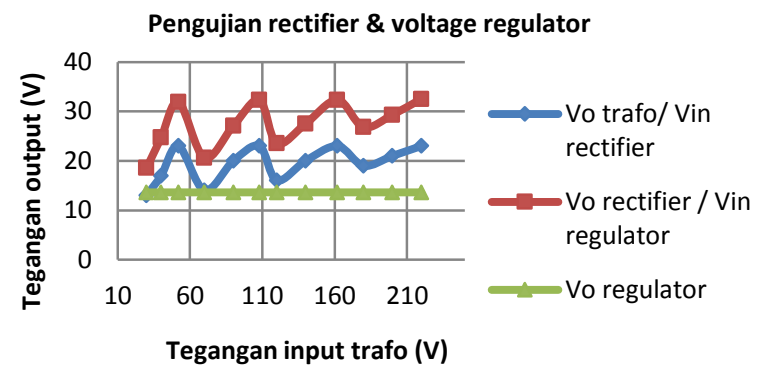

Gambar 19. Hasil pengujian rectifier \& voltage regualator Hasil pengujian inverter untuk beban resistif dapat dilihat pada gambar 20.

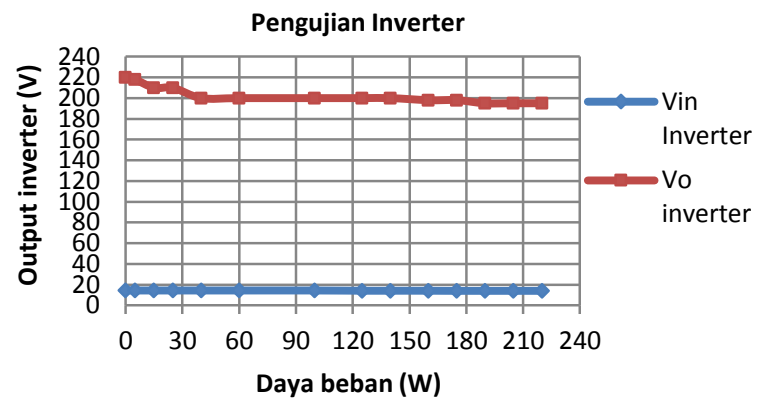

Gambar 20. Hasil pengujian inverter

Berdasarkan hasil pengujian inverter, beban output maksimal dari inverter adalah $220 \mathrm{~W}$. Jika beban di atas $220 \mathrm{~W}$, inverter akan fault atau gagal menghasilkan tegangan output karena beban yang terlalu tinggi.

\section{Pengujian rangkaian dengan kontroler fuzzy}

Pada pengujian ini, rangkaian motor generator dengan kontroler akan dibebani dengan beban resistif yang berupa lampu pijar. Sebelum terhubung ke beban, output generator tersambung ke regulator output yang terdiri dari komponen trafo regulator, rectifier, regulator tegangan, dan inverter.

Generator akan diputar dengan variasi rpm sesuai dengan variasi kecepatan generator pada turbin angin acuan. Perubahan kecepatan putar dan pembebanan akan mempengaruhi output dari kontroler yang mengatur eksitasi generator melalui komponen buck konverter.

Buck konverter ini mengatur tegangan output generator agar mencukupi untuk beban yang diberikan. Berikut adalah hasil pengujian rangkaian untuk beban resistif $75 \mathrm{~W}$. 


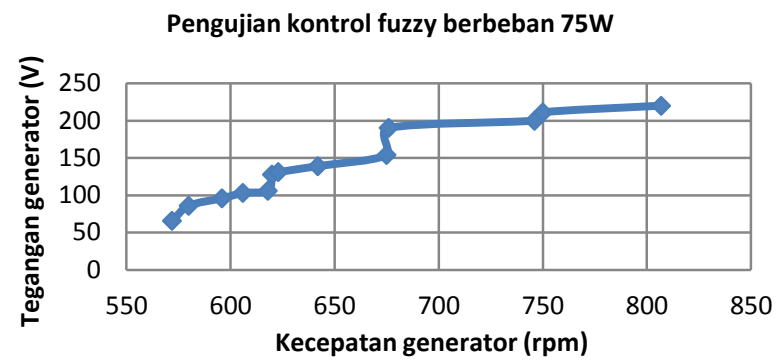

Gambar 21. Tegangan output generator dan rpm generator untuk beban $75 \mathrm{~W}$

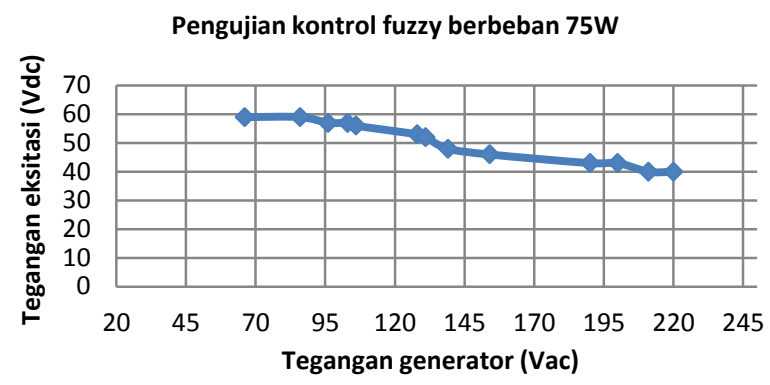

Gambar 22. Tegangan output generator dan eksitasi generator untuk beban $75 \mathrm{~W}$

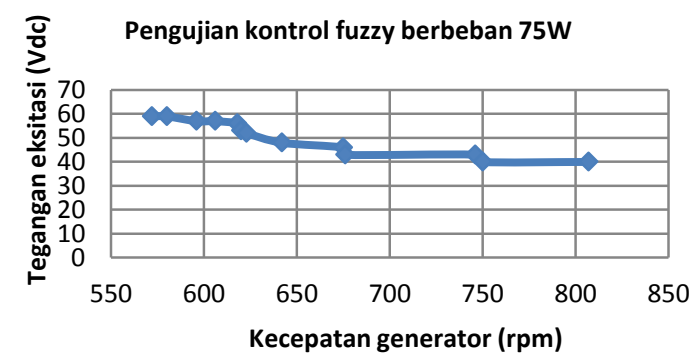

Gambar 23. Rpm generator dan eksitasi generator untuk beban $75 \mathrm{~W}$

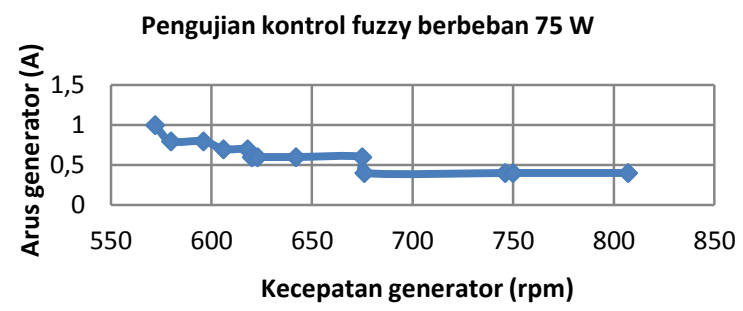

Gambar 24. Rpm generator dan arus generator untuk beban 75W

Berdasarkan hasil pengujian motor generator dengan kontroler fuzzy dapat disimpulkan disumpulkan sebagai berikut

$\checkmark$ Daya maksimum yang dapat ditanggung rangkaian adalah sebesar $190 \mathrm{~W}$ 
$\checkmark$ Kenaikan daya beban juga menaikkan tegangan eksitasi. Pengaturan ini dilakukan oleh kontroler dengan menaikkan nilai PWM. Nilai PWM yang dihasilkan menentukan tegangan output buck konverter sebagai pengatur besar kecilnya tegangan eksitasi.

$\checkmark$ Arus output generator dibatasi pada nilai 1 Ampere sesuai dengan spesifikasi generator pada tabel.

\section{Analisa unjuk kerja kontroler}

Kontroler logika fuzzy pada penelitian ini akan mengatur nilai tegangan eksitasi pada kumparan medan dari generator. Nilai tegangan eksitasi ini mempengaruhi besar kecilnya tegangan output dari generator. Tegangan eksitasi merupakan output dari rangkaian buck converter yang outputnya diatur oleh mikrokontroler. Mikrokontroler berfungsi sebagai kontroler logika fuzzy yang mengatur duty cycle pada buck converter. Tegangan output dari buck converter dipengaruhi oleh nilai duty cycle yang diberikan pada gate mosfet IRF740. Nilai tegangan output buck converter yang merupakan tegangan eksitasi generator memiliki tiga kondisi sesuai dengan rule output dari kontrol logika fuzzy yaitu high excitation $(\mathrm{HE})=60 \mathrm{Vdc}$, medium excitation $(\mathrm{ME})=50 \mathrm{Vdc}$, dan low excitation $(\mathrm{LE})=40 \mathrm{Vdc}$. Grafik respon dari nilai tegangan eksitasi untuk high excitation (HE) dapat ditunjukkan pada gambar 24.

Berdasarkan gambar 24, nilai steady state dari tegangan eksitasi generator adalah 59,21 Volt dari set point yang diharapkan adalah 60 Volt. Grafik pada gambar 4.26 dapat diperbesar untuk mengetahui respon dari tegangan eksitasi yang merupakan output dari kontroler logika fuzzy. Perbesaran ini dapat dilihat pada gambar 25.

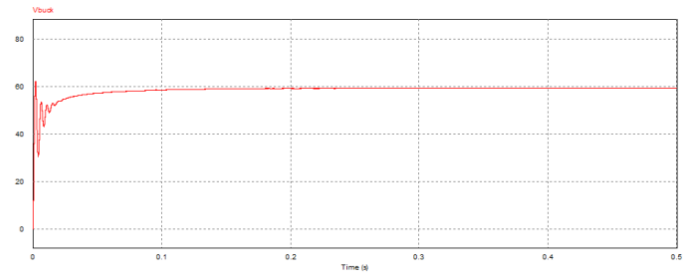

Gambar 25. Grafik output tegangan eksitasi untuk kondisi high excitation (HE)

Untuk melihat respon dari tegangan eksitasi, gambar 24 dapat diperbesar seperti pada gambar 25.

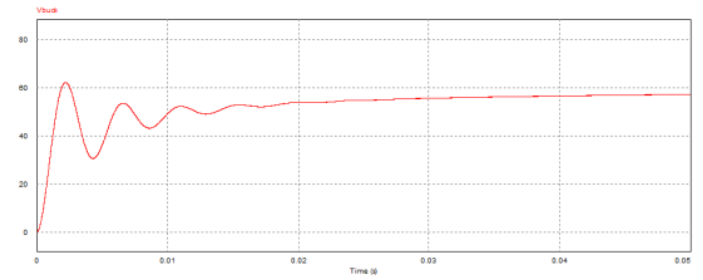

Gambar 26. Respon tegangan eksitasi untuk kondisi high excitation (HE)

Sesuai dengan gambar 25 dan respon untuk kondisi medium excitation (ME) serta untuk kondisi low excitation ( $L E)$, dapat disimpulkan bahwa respon dari tegangan eksitasi yang merupakan output dari kontrol logika fuzzy memiliki nilai parameter sebagai berikut :

Tabel 5. Karakteristik respon dari tegangan eksitasi

\begin{tabular}{|c|c|c|c|c|l|c|}
\hline Set & Steady & Delay & Rise & Peak & Settling & overshoot \\
Point & state & time & time & Time \\
$($ Vime & Timelt $)$ \\
$($ Volt $)$ & $(t d)$ & $(t r)$ & $(t p)$ & $(t s)$ & \\
& & & & & & \\
\hline
\end{tabular}




\begin{tabular}{|c|c|c|c|c|c|c|}
\hline 60 & 59,21 & $\begin{array}{c}0,986 \\
\mathrm{~ms}\end{array}$ & $\begin{array}{c}1,85 \\
\mathrm{~ms}\end{array}$ & $\begin{array}{c}2,20 \\
\mathrm{~ms}\end{array}$ & $\begin{array}{c}165,8 \\
\mathrm{~ms}\end{array}$ & 62,25 \\
\hline 50 & 50,54 & $\begin{array}{c}1,102 \\
\mathrm{~ms}\end{array}$ & $\begin{array}{c}1,80 \\
\mathrm{~ms}\end{array}$ & $\begin{array}{c}2,12 \\
\mathrm{~ms}\end{array}$ & $\begin{array}{c}150,9 \\
\mathrm{~ms}\end{array}$ & 53,03 \\
\hline 40 & 39,48 & $\begin{array}{c}0,981 \\
\mathrm{~ms}\end{array}$ & $\begin{array}{c}1,91 \\
\mathrm{~ms}\end{array}$ & $\begin{array}{c}2,23 \\
\mathrm{~ms}\end{array}$ & $\begin{array}{c}179,8 \\
\mathrm{~ms}\end{array}$ & 41,50 \\
\hline
\end{tabular}

Berdasarkan tabel 5, diperoleh nilai rata-rata dari respon tegangan eksitasi adalah sebagai berikut

- Delay time $(t d) \quad: 1,02 \mathrm{~ms}$

- Rise time (tr) : $1,85 \mathrm{~ms}$

- Peak time (tp) : $2,18 \mathrm{~ms}$

- Settling time (ts) : $165,5 \mathrm{~ms}$

- Maximum overshoot : $5 \%$

Tegangan output generator dipengaruhi oleh beberapa faktor yaitu nilai tegangan eksitasi, kecepatan putar generator dan pembebanan. Output pada kontrol logika fuzzy ini yaitu tegangan eksitasi dibagi menjadi tiga kondisi yaitu high excitation $(H E)$, medium excitation $(M E)$, dan low excitation $(L E)$. Sedangkan input kontrol logika fuzzy yaitu kecepatan putar generator dan tegangan output generator. Input kecepatan putar generator dibedakan menjadi tiga kondisi yaitu high rpm (HR), medium rpm $(M R)$ dan low rpm $(L R)$. Sedangkan input tegangan generator dibedakan menjadi tiga kondisi yaitu high voltage $(H V)$, medium voltage $(M V)$ dan low voltage $(L V)$.

Dengan menggunakan kontrol logika fuzzy, perubahan nilai input akan menghasilkan nilai output yang berbeda untuk menjamin agar generator tetap bisa mensuplai beban dengan berbagai kondisi input yang ada sesuai dengan pengujian yang telah dilakukan.

Pada kondisi output tegangan eksitasi high excitation $(H E)$, nilai tegangan generator dapat diperoleh sesuai grafik berikut :

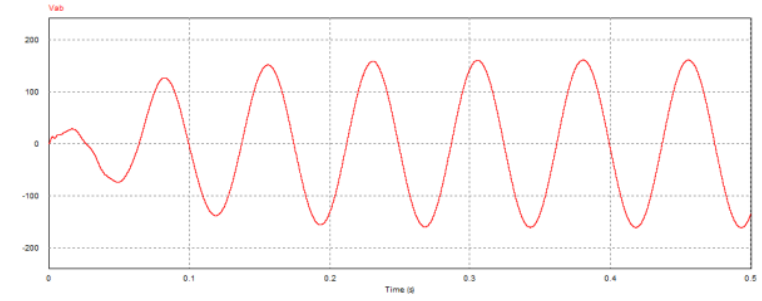

Gambar 27. Tegangan output generator untuk kondisi high excitation (HE)

Nilai tegangan output generator sesuai gambar 26 adalah $V_{\max }=160,82$ Volt dengan $V_{\text {rms }}=$ 103,83 Volt. Untuk kecepatan putar generator pada kondisi ini dapat ditunjukkan pada gambar 27.

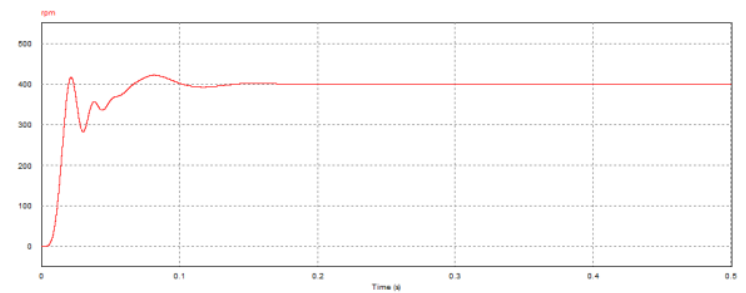

Gambar 28. Kecepatan putar generator untuk kondisi high excitation $(H E)$ 
Kecepatan putar generator pada gambar 27 adalah 399,86 rpm. Nilai tegangan output generator dan kecepatan putar generator pada gambar 26 dan 27 adalah pada kondisi low voltage $(L V)$ dan low rpm (LR).

Sesuai dengan rule base kontrol logika fuzzy pada tabel 4, maka seharusnya nilai output dari kontrol fuzzy untuk kondisi low voltage $(L V)$ dan low rpm $(L R)$ adalah pada kondisi high excitation $(H E)$. Berdasarkan pada kondisi ini maka dapat disimpulkan bahwa kontrol logika fuzzy telah bekerja sesuai dengan yang diharapkan.

\section{KESIMPULAN}

Rangkaian kontrol generator sinkron tiga fasa dengan penggerak turbin angin terdiri dari tiga rangkaian utama yaitu rangkain buck converter sebagai pengontrol eksitasi generator, rangkaian regulator tegangan sebagai pengontrol output generator dan kontrol logika fuzzy sebagai pengontrol buck converter.

Sistem kontrol buck converter menggunakan mikrokontroler Arduino Mega 2560 sebagai kontroler fuzzy dengan didukung sensor tegangan dan sensor rpm. Kinerja respon kontrol logika fuzzy pada pengaturan tegangan eksitasi oleh buck converter adalah 1,02 ms untuk delay time, 1,85 ms untuk rise time, 2,18 ms untuk peak time, 165,5 ms untuk settling time dan dengan maximum overshoot sebesar $5 \%$. Disain rangkaian kontrol memiliki kinerja yang baik untuk berbagai variasi kecepatan putar generator dan perubahan beban karena memiliki tegangan output dan frekuensi output yang stabil.

\section{DAFTAR PUSTAKA}

[1]. Airlangga Guruh Pratama (2012), "Perancangan Kincir Angin Tipe Axial Sebagai Pembangkit Tenaga Listrik", Jurusan Teknik Elektro Fakultas Teknik Universitas Muhammadiyah Surakarta, Juli 2012.

[2]. Ahmed F Zobaa, Ramesh Bansal. "Handbook of Renewable Energy Technology”, World Scientific Publishing Co. Pte. Ltd., 2011.

[3]. Airlangga Guruh Pratama (2012), "Perancangan Kincir Angin Tipe Axial Sebagai Pembangkit Tenaga Listrik", Jurusan Teknik Elektro Fakultas Teknik Universitas Muhammadiyah Surakarta, Juli 2012.

[4]. Labtech International Ltd,(2010), "Motor generator sistem trainer (Experiment manual) Model:LEM-MGS”, Labtech Knowledge Engineering, Batam, 2010.

[5]. .Md Maruf Hossain, Mohd. Hasan Ali (2015) "Future research direction for the wind turbine generator system”, Renewable and Sustainable Energy Reviews, pg.481-489.

[6]. Om Prakash Mahela, Abdul Gafoor Shaik (2016), "Comprehensive overview of grid interfaced wind energy”, Renewable and Sustainable Energy Reviews, pg.260-281.

[7]. Rifdian Indrianto Sudjoko, Purwadi Agus Darwito, "Design and simulation of generator excitation system using buck converter at motor generator trainer model LEM-MGS", International Conference on Advanced Mechatronics, Inttelligence Manufacture and Industrial Automation (ICAMIMIA), 2017

[8]. Shreenidhi Pisharody, V Vanitha, "DC-DC chopper excitation control of WRSG for MPPT in offshore wind farm”,(2015), ScienceDirect Procedia Technology 21, pg. 643-650.

[9]. Tahir Khalfallah, Belfedal Cheikh, Allaoui Tayeb, Gerard Champion, (2015), "Power Control of Wind Turbine Based on Fuzzy Sliding Mode Control”, International Journal of Power Electronics and Drive System (IJPEDS), Vol.5, No.4, pg.502-511. 